\title{
Helen Salisbury: Testing times for GPs
}

\author{
Helen Salisbury GP \\ Oxford
}

Patients often turn to their GP for advice on how to stay safe in this uncertain world, to help them apply the rules to their own health condition. They expect us to have privileged access to the latest developments, but in this pandemic we find out about the next policy move only by listening to the news.

When it comes to coronavirus antigen testing, GPs have mostly been sitting on the sidelines, frustrated by being unable to request tests for symptomatic patients and not receiving the results of tests done elsewhere. It was announced this week that all patients with symptoms will be able to get an antigen test through NHS 111. They can choose between a self-test kit or an appointment at a drive-through centre.

I'm delighted that my patients can finally access tests, but there are significant problems with what is proposed. Worryingly, the government website states: "A negative result means you did not have coronavirus when the test was done." No nuance, cautions, or ifs-and-buts. This statement is clearly not true, as the false negative rate of self-swabs for coronavirus is estimated at roughly $30 \%$. $^{2}$ It's not clear how much this is due to the inconsistent presence of the virus in the nasopharynx and how much to the difficulty of correctly taking the swabs.

The meaning of a result depends not only on the accuracy (sensitivity and specificity) of the test but also on the context. I'm not an expert in statistics, but the concept of pre-test probability is important-and here it depends both on the amount of circulating virus in the community and on the nature of the symptoms that prompted the test. If the patient had a fever, dry cough, and anosmia it would be unwise to trust a negative result.

Most doctors spend time every day explaining test results to patients, teasing out ambiguities, and working out a plan with the patient. In this case, however, GPs are not included in this process at any point, so we'll have no opportunity to explain. With increasing pressure to return to work, as employers struggle with reducing government furlough payments, it's easy to predict that patients who have a negative swab won't self-isolate, even if they feel unwell, thus pushing up the coronavirus transmission rate.

To add to the confusion, some general practices (although not mine) have received notification that antibody tests will be rolled out very soon. A letter from NHS England and NHS Improvement says that these should be requested when clinically indicated but may also be offered to patients who have blood tests for other reasons and wish to know whether they've been infected with covid-19. We're already receiving multiple requests for antibody testing, which we cannot yet offer. We're recording a message for our surgery phone to this effect, as we anticipate our reception team being inundated with calls as soon as this policy is announced.

The only official communication about antibody testing we've had so far is through the grapevine-but I may listen to the government briefing this evening, so at least I'll know as much as my patients.

Competing interests: See www.bmj.com/about-bmj/freelance-contributors. Provenance and peer review: Commissioned; not externally peer reviewed.

1 NHS. What your coronavirus test result means. 27 May 2020. https://www.nhs.uk/ conditions/coronavirus-covid-19/testing-for-coronavirus/what-your-coronavirus-test-resultmeans/.

2 Brooks M. How accurate are the results from self-testing for covid-19 at home? New Scientist 2020 May 13. https://www.newscientist.com/article/mg24632823-200-howaccurate-are-the-results-from-self-testing-for-covid-19-at-home/.

Published by the BMJ Publishing Group Limited. For permission to use (where not already granted under a licence) please go to http://group.bmj.com/group/rights-licensing/ permissions 